\title{
Retención urinaria aguda y hematuria secundarias a metástasis peneanas por carcinoma renal de células claras
}

\author{
C. Pascual Mateo*, M.A. Nieto Gallo**, M. Luján Galán*, C. Santonja Garriga**, \\ N. Rodríguez García*, A. Berenguer Sánchez*
}

*Servicio de Urología, ${ }^{* *}$ Servicio de Anatomía Patológica. Hospital Universitario de Getafe. Madrid.

Actas Urol Esp 2005; 29 (6): 593-595

\section{RESUMEN}

\section{RETENCIÓN URINARIA AGUDA Y HEMATURIA SECUNDARIAS A METASTASIS PENEANAS POR CARCINOMA RENAL DE CÉLULAS CLARAS}

El carcinoma renal de células claras es una neoplasia con gran capacidad de diseminación y que se presenta de formas muy variadas. Presentamos un caso clínico de un sujeto que desarrolla hematuria y retención aguda de orina secundarias ambas a metástasis en pene de un carcinoma renal de células claras. A continuación se lleva a cabo una pequeña revisión de la literatura existente sobre metástasis en esta localización.

Palabras clave: Metástasis peneana. Carcinoma renal células claras. Hematuria. Retención aguda de orina.

\section{ABSTRACT}

\section{ACUTE URINARY RETENTION AND HEMATURIA SECONDARY TO METASTATIC RENAL} CLEAR-CELL CARCINOMA TO THE PENIS

Renal cell carcinoma have a great capacity of dissemination and have a great variety of clinical presentation. We exposed a clinical note of a patient diagnosed of renal cell carcinoma who developed hematuria and acute urinary retention due to a penis metastasis. Next we review the literature about this topic.

Keywords: Penis metastasis. Renal cell carcinoma. Hematuria. Acute urinary retention.

$\mathrm{E}_{\mathrm{d}}^{\mathrm{s}}$ carcinoma de células renales supone un 3\% de los tumores malignos en los adultos. Su forma de presentación es variable pudiendo diagnosticarse tanto como un hallazgo incidental (50\% en los casos), como síntomas locales, paraneoplásicos o en forma metastásica, sobre todo en pulmón, hígado y hueso, aunque se han descrito una gran variedad de localizaciones $^{1,2}$, entre ellas en pene.

En este trabajo presentamos un caso de carcinoma renal de células claras con metástasis peneana y una revisión de la literatura sobre esta patología.

\section{CASO CLÍNICO}

Varón de 66 años con antecedentes de tabaquismo, diabetes mellitus, hipertensión arterial, hipercolesterolemia, EPOC severo, fibrilación auri- cular; antecedentes urológicos de hipertrofia de próstata e impotencia coeundi en tratamiento con alfa-bloqueantes y prostanglandina $\mathrm{E}$ intracavernosa y antecedentes quirúrgicos de estenosis aórtica y mitral con angina de esfuerzo que precisó doble recambio valvular.

A raíz de la cirugía de recambio valvular queda con una insuficiencia renal crónica por lo que es remitido a consultas de Nefrología, los cuales durante su estudio objetivan en ecografía abdominal una masa en riñón izquierdo de 13x9 cm, una hipercalcemia y hematuria microscópica. En el CT de abdomen se observa una masa renal izquierda con infiltración de órganos vecinos $\mathrm{y}$ trombo en vena renal I, y una radiografía tórax y gammagrafía normales. 
Posteriormente el paciente presenta un cuadro de retención aguda de orina con hematuria que precisa sondaje; tras éste el sujeto desarrolla uretrorragia maloliente que evoluciona mal a pesar de tratamiento médico hacia gangrena de pene que precisa penectomía total y cistostomía suprapúbica. El paciente sufre deterioro progresivo y fallece a los 15 días de la penectomía. En la necropsia se objetiva un Carcinoma de células renales de célu-

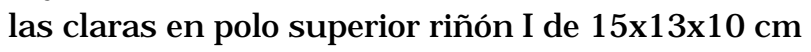
con gran extensión local a órganos vecinos, trombo tumoral en vena renal I, embolismo en cuerpos cavernosos pene, metástasis hepática de $7 \mathrm{~mm}$ y microangiopatía trombótica tumoral pulmonar (pT4NxM1) (Figs. 1, 2, 3 y 4).

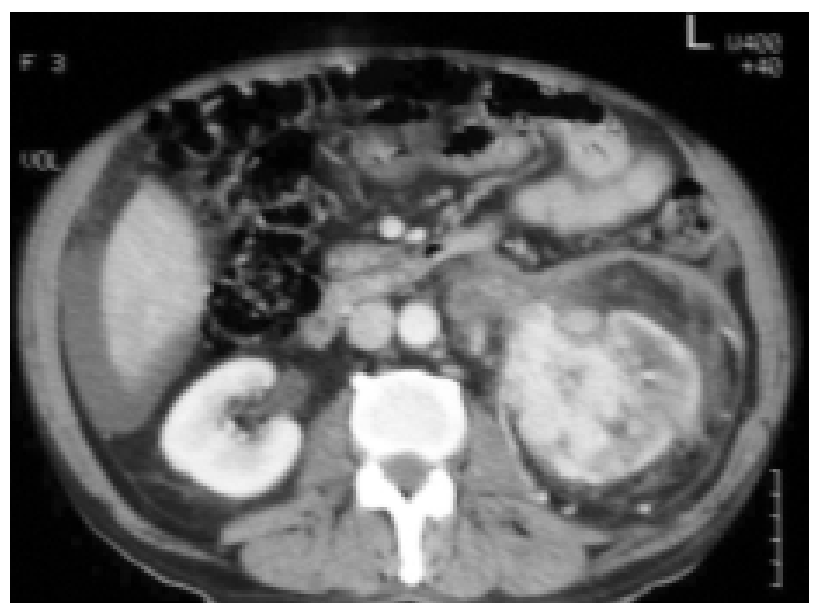

FIGURA 1. Corte transversal de CT abdomen en el que se observa una gran masa en riñón izquierdo que infiltra grasa $y$ órganos vecinos y un trombo en vena renal izquierda.

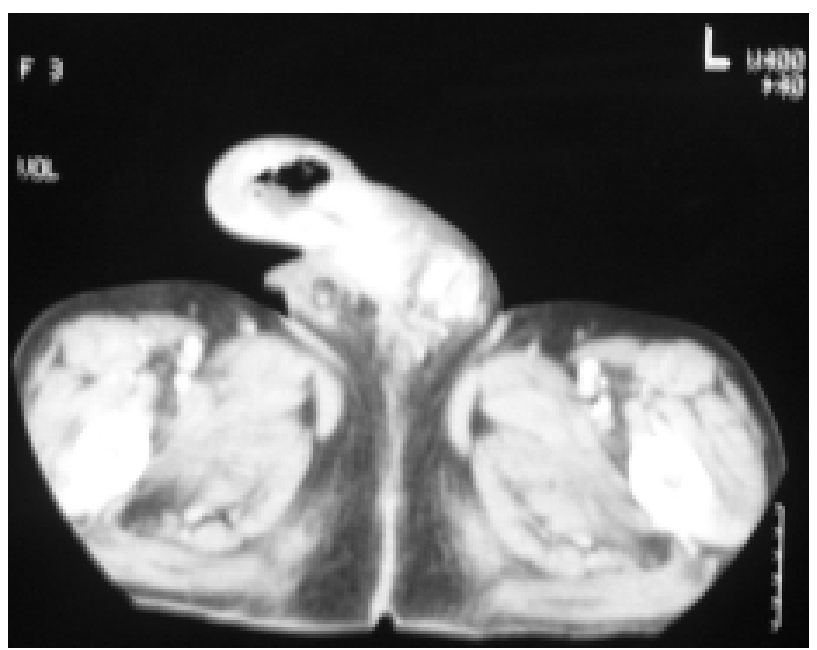

FIGURA 2. Corte axial de CT pélvico en donde se objetiva una masa a nivel de cuerpos cavernosos izquierdos $y$ necrosis en glande.

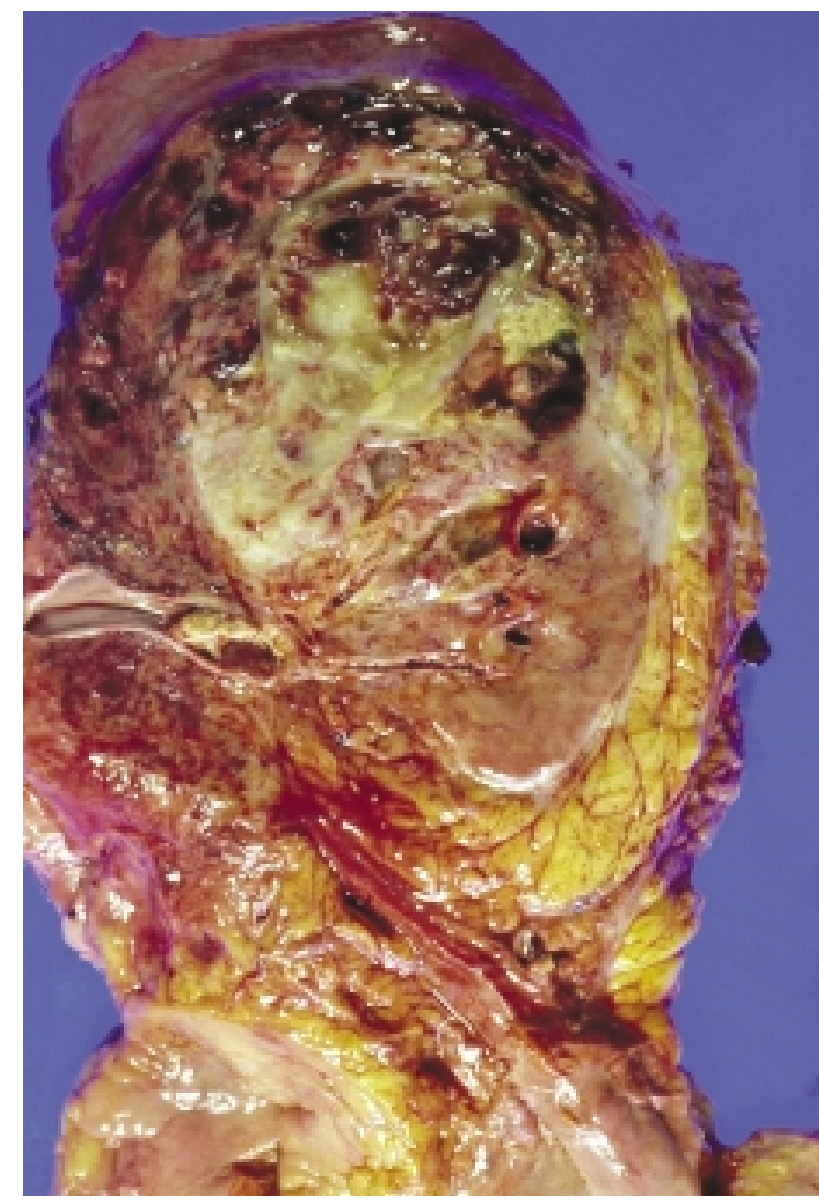

FIGURA 3. Imagen macroscópica de riñón izquierdo, donde se objetiva la masa tumoral y el trombo en la vena renal.

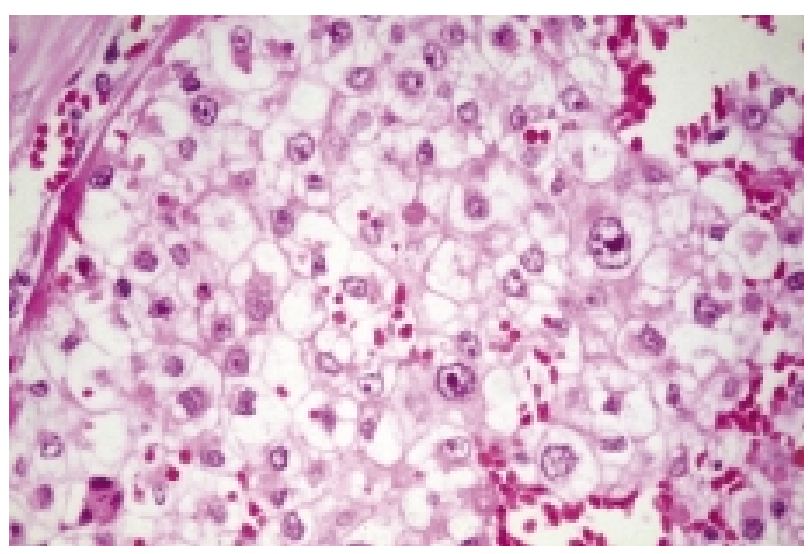

FIGURA 4. Imagen microscópica de las metástasis peneanas cavernosas sonde se observan células tumorales de citoplasmas claro y eritrocitos en senos vasculares.

\section{DISCUSION}

El pene, a pesar de su rica vascularización sanguínea y linfática, se ve poco afectada por metástasis: El primer caso fue descrito por Eberth; tras éste se han publicado aproximadamente un total 
de 300 casos, de ellos menos de 30 por CCR, recogidas en revisiones como Abeshouse ${ }^{3}$, Ordóñez ${ }^{4}$, Daniels $^{5}$, Powell ${ }^{6}$ y Hashimoto ${ }^{7}$.De los 219 casos recogidos por Powell, un 92\% eran carcinomas y un $10,5 \%$ procedian del riñón, siendo las tumores primarios más frecuentes los de vejiga, próstata, colorrectal y riñón ${ }^{6}$. Hasta 1991 se recogen 20 casos 5, habiéndose identificado algunos casos más hasta este momento, sin llegar a superar los 30 casos descritos en la literatura ${ }^{5}$.

Nuestro caso se trata de una metástasis peneana por un CCR, que debutó con retención aguda de orina y hematuria; el tiempo entre el diagnóstico de la masa renal y los sintomas fue de 6 meses. Mientras que para Abeshouse la existencia de metástasis en el momento del diagnóstico era rara, Powell encuentra que hasta un 30\% estaban presentes ${ }^{3,6}$.

En cuanto a las rutas de diseminación metastásica hacia el pene, se citan clásicamente 3 rutas: extensión directa, vía venosa retrógrada y la embolización arterial ${ }^{6}$. En cuanto a las vías de diseminación venosa del CCR, se postulan 3 vías: vía vena renal a vena cava, vía vena espermática a órganos pélvicos y vía venas vertebrales (plexo de Batson) ${ }^{2}$.

En cuanto a las formas de presentación, la presencia de una masa o hinchazón difusa del pene parece ser lo más frecuente, junto con el priapismo maligno(de Peacock) (40\%); también se han descrito retención de orina, dolor, ulceraciones, hematuria y disuria. El priapismo maligno es una forma de presentación relativamente frecuente en estos casos por afectación de los cuerpos caverno$\operatorname{sos}^{4-8}$. El diagnostico diferencial se plantea con lesiones tumorales (primarios de pene) y no neoplásicas (chancro, chancroide, lesiones inflamatorias, tuberculosis, otras). En el momento de presentarse la retención de orina no objetivamos otros signos de enfermedad metastásica, aunque en dos tercios de los casos sí suelen estar presentes.
La opción terapéutica en este caso fue la penectomía total; para Hashimoto es el tratamiento de elección ante CCR extirpable y lesión única, en los casos con retención de orina o dolor no tratable y como tratamiento paliativo en pacientes con buen estado; para Haddad solo se indica cuando es la única afectación metastási$\mathrm{ca}^{5-9}$. Algunos autores han encontrado respuestas más o menos buenas a otros tratamientos como hipertermia, radioterapia, quimioterapia, pero aún así el pronóstico es francamente malo y en su mayor parte mueren dentro del primer año (unas 6 semanas en el caso de neoplasias genitourinarias), mejorando discretamente cuando se intervienen quirúrgicamente.

\section{REFERENCIAS}

1. Who. Globocan. www.who.org.

2. Wahner-Roedler DL, Sebo TJ. Renal cell carcinoma: diagnosis based on metastatic manifestations.

3. Abeshouse BS, Abeshouse GA. Metastatic tumors of the penis: a review of the literature and a report of two cases. $J$ Urol 1961;86:99-112.

4. Ordoñez NG, Ayala AG, Bracken RB. Renal cell carcinoma metastatic to penis. Urology 1982;19:417-419

5. Daniels GF, Schaeffer AJ. Renal cell carcinoma involving penis and testis: unusual initial presentations of metastatic disease. Urology 1991;37:369-373.

6. Powell BL, Craig JB, Muss HB: Secondary malignancies of the penis and epididymis: a case report and review of the literature; Journal Clin Oncol 1985;3:110-116.

7. Hashimoto H, Saga Y, Watabe Y, et al. Case report: secondary penile carcinoma. Urol Int 1989;44:56.

8. McIntyre IG, Burgess NA, Roberts PF. Penile metastasis from renal cel carcinoma; BJU 1996;77:654-755.

9. Haddad FS. Penile metastasis secondary to bladder cancer. Urol Int 1984;39:125-142.

Dr. C. Pascual Mateo

Servicio de Urología

Hospital de Getafe

Carretera de Toledo, Km. 12,500

Getafe Madrid

(Trabajo recibido el 4 octubre de 2004) 